Pesq. Vet. Bras. 28(3):169-173, março 2008

\title{
Intoxicação por larvas de Perreyia flavipes em bovinos na região sul do Rio Grande do Sul ${ }^{1}$
}

\author{
Mauro P. Soares², Pedro S. Quevedo ${ }^{3}$ e Ana Lucia Schild²*
}

\begin{abstract}
Soares M.P., Quevedo P.S. \& Schild A.L. 2008. [Perreyia flavipes larvae poisoning in cattle in southern Rio Grande do Sul, Brazil.] Intoxicação por larvas de Perreyia flavipes em bovinos na região sul do Rio Grande do Sul. Pesquisa Veterinária Brasileira 28(3):169-173. Laboratório Regional de Diagnóstico, Faculdade de Veterinária, Universidade Federal de Pelotas, Campus Universitário s/n, Pelotas, RS 96010-900, Brazil. E-mail: alschild@terra.com.br

Three outbreaks of poisoning by Perreyia flavipes Konow, 1899 (Hymenoptera: Pergidae) in cattle during July and August 2006 in southern Brazil are reported. The morbidity rate was $0.8 \%, 6.2 \%$ and $33 \%$ on the 3 farms, respectively. Fatality rate was $100 \%$. Clinical signs were depression, jaundice, recumbence, pedaling movements and death in 24-48 hours. The liver was enlarged with increased lobular pattern, the mesenteric lymph nodes were edematous and Peyer patches of the small gut were depressed. Petechial hemorrhages and ecchymosis were observed in the mesentery and abomasum. On histologic examination the liver showed centrolobular or massive necrosis. Hemosiderosis and necrosis of the germinative centers of lymph nodes, white pulp of the spleen and Peyer patches were also observed. The poisoning occurred probably due to an intense drought in October-December 2005, when the insect stayed as a cocoon underground. The dry conditions probably avoided a higher number of adult sawflies to emerge from the cocoons, what resulted in greater egg production. The large amount of decaying grass due to almost normal rain fall during summer seemed to have provided favorable environmental conditions for the development of larvae in winter.
\end{abstract}

INDEX TERMS: Perreyia flavipes, sawfly, epidemiology, bovine, hepatic necrosis.

RESUMO.- Descrevem-se três surtos de intoxicação por larvas de Perreyia flavipes Konow, 1899 (Hymenoptera: Pergidae) ocorridos em bovinos durante os meses de julho e agosto de 2006. A morbidade foi de $0,8 \%, 6,2 \%$ e $33 \%$ nos três estabelecimentos, respectivamente. A letalidade foi de $100 \%$. Os sinais clínicos nos três surtos caracterizaram-se por depressão, icterícia, decúbito com movimentos de pedalagem e morte em 24-48 horas. Macroscopicamente o fígado dos animais necropsiados estava aumentado de tamanho e com marcada acentuação do padrão lobular, os linfonodos hepáticos e mesen-

\footnotetext{
${ }^{1}$ Recebido em 12 de novembro de 2007. Aceito para publicação em 6 de dezembro de 2007.

2 Laboratório Regional de Diagnóstico, Faculdade de Veterinária, Universidade Federal de Pelotas, Campus Universitário s/n, Pelotas, RS 96010-900, Brasil. *Autor para correspondência: alschild@ terra.com.br

${ }^{3}$ Bolsista de Iniciação Científica, aluno de Graduação, Faculdade de Veterinária, Universidade Federal de Pelotas, RS.
}

téricos estavam edemaciados e as placas de Peyer na mucosa do intestino delgado estavam deprimidas. Petequias e equimoses foram observadas no mesentério e abomaso. Histologicamente observou-se degeneração e necrose hemorrágica hepática que variou de centrolobular, se estendendo a região a mediozonal, ou massiva. Havia, ainda, marcada hemossiderose e necrose dos centros germinativos dos linfonodos, da polpa branca do baço e das placas de Peyer no intestino. A intoxicação ocorreu provavelmente em conseqüência da intensa seca observada na região nos meses de outubro a dezembro de 2005, período em que o inseto se encontra na forma de casulo enterrado no solo. A seca proporcionou maior emergência de adultos e conseqüentemente maior quantidade de posturas. A grande quantidade de matéria vegetal em decomposição devido às precipitações próximas do normal no verão proporcionou ambiente ideal para o desenvolvimento das larvas no período de inverno o que provavelmente levou à intoxicação. 
TERMOS DE INDEXAÇÃO: Perreyia flavipes, bicho mata-porco, epidemiologia, bovinos, necrose hepática.

\section{INTRODUÇÃO}

Larvas de diferentes espécies de insetos himenópteros têm sido descritas como tóxicas para animais domésticos. Na Austrália são descritos surtos de intoxicações espontâneas em bovinos e ovinos pela ingestão das larvas de Lophyrotoma interrupta (sawfly) (Pergidae) (McKenzie et al. 1985). Na Dinamarca, larvas de Arge pullata (Argidae) presentes em bosques de Betula pendula, causaram intoxicação em ovelhas (Thamsborg et al. 1987).

Perreyia flavipes Konow, 1899 (Perreyiinae, Pergidae; Hymenoptera) (bicho-da-chuva, bicho-mata-porco, carestia) tem sido encontrada na Argentina (Smith 1990), no Uruguai (Dutra et al. 1997) e no Brasil nos estados do Espírito Santo, Rio Grande do Sul, Santa Catarina e Distrito Federal (Smith 1990).

No Uruguai são relatados surtos de intoxicação espontânea em bovinos e ovinos por larvas de $P$. flavipes com uma incidência de 3-28\% (Dutra et al. 1997, Dutra 2003). Este autor associa os surtos a condições climáticas tais como o excesso de chuva na primavera e verão e o acúmulo de forragem no outono que podem ser um indicativo de risco e previsão de ocorrência da intoxicação no inverno.

O ciclo de $P$. flavipes foi reproduzido em laboratório sendo observado que dura o ano todo (Soares et al. 2000). As larvas aparecem nas pastagens a partir de março, possuem cerca de $1 \mathrm{~mm}$ e apresentam coloração preta brilhante, mas são notadas facilmente somente de maio a setembro quando medem 17-22mm. Alimentam-se de matéria vegetal em decomposição, folhas secas e fezes de bovino secas. Durante o estágio larval sofrem várias mudas até atingirem o momento da pupagem, quando o inseto penetra no solo e a uma profundidade de $3-10 \mathrm{~cm}$ tece um casulo de formato ovóide, coloração preta briIhante e aspecto couriáceo medindo aproximadamente $1 \mathrm{~cm}$ de comprimento e $0,5 \mathrm{~cm}$ de largura. No interior do casulo a larva assume uma coloração branca amarelada e permanece neste estágio de agosto até janeiro quando emerge o adulto que imediatamente inicia o novo ciclo de reprodução, pois tem curto período de vida. Os insetos adultos têm coloração preta brilhante. A fêmea tem 8$10 \mathrm{~mm}$ e vive durante de 18-36 horas após a emergência. O macho tem 7,5-10 mm de comprimento vive durante 2448 horas após a emergência (Soares et al. 2000).

Dois princípios tóxicos têm sido isolados das larvas de $P$. flavipes: pergidina $(0,036 \%)$ que é um heptapeptídeo contendo um resíduo fosfoseril e lofirotomina que é um octapeptídeo (0,034\%) (Oelrichs et al. 1999). Experimentalmente a dose tóxica de larvas para ovinos e suínos é de $10 \mathrm{~g} / \mathrm{kg}$ de peso vivo. Em bovinos a intoxicação foi reproduzida com $40 \mathrm{~g} / \mathrm{kg}$ de peso vivo e a morte ocorreu em 24 horas (Dutra et al. 1997, Soares et al. 2000).

A possível intoxicação espontânea de suínos por larvas de insetos himenópteros, possivelmente de $P$. flavipes no Brasil, durante o inverno tem sido sugerida por vários produtores rurais e técnicos dos estados da região sul desde 1946 (Rodrigues Camargo 1955), no entanto não há descrição e diagnóstico confirmado destes surtos.

Os objetivos deste trabalho foram descrever a epidemiologia, os sinais clínicos e a patologia de 3 surtos de intoxicação por $P$. flavipes em bovinos ocorridos no ano 2006 na área de influência do Laboratório Regional de Diagnóstico (LRD) da Faculdade de Veterinária, UFPel.

\section{MATERIAL E MÉTODOS}

Os dados epidemiológicos e os sinais clínicos dos 3 surtos foram obtidos durante as visitas realizadas nas propriedades onde ocorreram as mortes. Os dados climatológicos foram obtidos na estação Agroclimatológica de Pelotas, Rio Grande do Sul.

Foram realizadas 5 necropsias em animais recém mortos ou eutanasiados in extremis. Para o estudo histológico das lesões foram coletados os diversos órgãos das cavidades abdominal e torácica, bem como o sistema nervoso central, os quais foram fixados em formol tamponada $10 \%$. Fragmentos de todos os órgãos foram cortados com $5 \mu \mathrm{m}$ de espessura, incluídos em parafina e corados pela técnica de hematoxilina-eosina (HE). O sistema nervoso central foi cortado transversalmente obtendo-se cortes das seguintes regiões: córtex frontal, parietal e occipital, núcleos da base, tálamo, colículos rostrais, ponte e pedúnculos cerebelares, cerebelo e bulbo na altura do óbex, que foram também cortados com $5 \mu \mathrm{m}$ de espessura e corados por HE.

\section{RESULTADOS}

\section{Epidemiologia}

A intoxicação foi observada em 3 propriedades localizadas nos municípios de Candiota (Propriedade 1), Canguçu (Propriedade 2) e São Lourenço do Sul (Propriedade 3) entre julho e agosto de 2006. Na Propriedade 1 morreram 5 animais de um lote de 80 novilhos de 1-2 anos de idade, que estavam em uma área de campo nativo. Na Propriedade 2 os animais estavam fracos e foram colocados em uma pastagem de Lolium multiflorum (azevém), morrendo no dia seguinte. Na Propriedade 3 morreram 32 animais de um total de 110 novilhos de 2 anos, que estavam em campo nativo. Na Propriedade 3, de acordo com o proprietário 3 ovelhas e um cordeiro de um total de 168 animais haviam morrido na mesma área alguns dias antes dos bovinos adoecerem. O resumo dos dados epidemiológicos são apresentados no Quadro 1.

Quadro 1. Dados epidemiológicos dos surtos de intoxicação por Perreyia flavipes ocorridos em bovinos no sul do Rio Grande do Sul

\begin{tabular}{lccccccc}
\hline Município & $\begin{array}{c}\text { Mês Idade } \\
\text { (meses) }\end{array}$ & sob risco & & & $\begin{array}{c}\text { Animais Afetados Mortos } \\
\text { sorbi- Letali- } \\
\text { dade } \\
\text { (\%) }\end{array}$ & $\begin{array}{c}\text { dade } \\
(\%)\end{array}$ \\
\hline Candiota & Julho & $12-24$ & 80 & 5 & 5 & 6,2 & 100 \\
Canguçu & Agosto & 36 & 250 & 2 & 2 & 0,8 & 100 \\
São Louren- & Agosto & 24 & 110 & 32 & 32 & 33,5 & 100
\end{tabular}

ço do Sul 
Quadro 2. Ciclo de vida de Perreyia flavipes e precipitação pluviométrica média, média acumulada, média máxima em 24 horas e normais para a região sul do Rio Grande do Sul de setembro de 2005 a agosto de $2006^{a}$

\begin{tabular}{|c|c|c|c|c|c|c|c|c|c|}
\hline \multirow{2}{*}{$\begin{array}{l}\text { Estágio } \\
\text { de vida de } \\
P . \text { flavipes }\end{array}$} & \multicolumn{9}{|c|}{ Precipitação (mm) } \\
\hline & Mês/ano & Média & Normal & $\begin{array}{c}\text { Média } \\
\text { acumulada }\end{array}$ & $\begin{array}{c}\text { Acumulada } \\
\text { (normal) }\end{array}$ & $\begin{array}{c}\text { Média } \\
\text { máxima em } \\
24 \text { horas }\end{array}$ & $\begin{array}{l}\text { Precipitação } \\
\text { máxima em } \\
24 \text { horas } \\
\text { (normal) }\end{array}$ & $\begin{array}{l}\text { № de dias } \\
\text { com pre- } \\
\text { cipitação }\end{array}$ & $\begin{array}{l}\text { № de dias } \\
\text { com pre- } \\
\text { cipitação } \\
\text { (normal) }\end{array}$ \\
\hline Larva/pupa & 9/2005 & 241,6 & 123,7 & 241,6 & 125,5 & 85,2 & 92,0 & 14 & 10,8 \\
\hline Pupa & $10 / 2005$ & 93,3 & 100,7 & 93,3 & 97,8 & 24,4 & 74,7 & 13 & 10,6 \\
\hline Pupa & $11 / 2005$ & 23,7 & 99,5 & 23,7 & 100,0 & 19,2 & 81,6 & 4 & 10 \\
\hline Pupa/adulto & $12 / 2005$ & 54,6 & 103,2 & 45,6 & 103,3 & 20 & 152,0 & 11 & 9,5 \\
\hline Adulto/ovo & $1 / 2006$ & 113,8 & 119,1 & 122,8 & 115,9 & 27,8 & 82 & 13 & 11,7 \\
\hline Ovo /larvab & $2 / 2006$ & 82,8 & 153,3 & 82,8 & 157,7 & 37,2 & 188,2 & 12 & 11,5 \\
\hline Ovo /larvab & $3 / 2006$ & 135,6 & 97,4 & 135,6 & 96,9 & 55,4 & 126,8 & 6 & 10,3 \\
\hline Larva $^{\mathrm{b}}$ & $4 / 2006$ & 30,2 & 100,3 & 30,2 & 101,3 & 22 & 134 & 8 & 8,9 \\
\hline Larva & $5 / 2006$ & 58,4 & 100,7 & 58,4 & 101,7 & 14,2 & 86,0 & 14 & 9,2 \\
\hline Larva & $6 / 2006$ & 61,2 & 105,7 & 61,2 & 104,6 & 21,2 & 95,0 & 10 & 10,5 \\
\hline Larva/pupa & $7 / 2006$ & 79,2 & 146,0 & 79,2 & 147,2 & 30,4 & 109,8 & 8 & 11,4 \\
\hline Larva/pupa & $8 / 2006$ & 109,8 & 117,4 & 109,8 & 116,1 & 33,8 & 92,2 & 11 & 9,7 \\
\hline
\end{tabular}

a Dados obtidos nos Boletins Agroclimatológicos, Estação Agroclimatológica de Pelotas, Convênio Embrapa/UFPel/Inmet.

b Larvas de primeiros estágios.

Os dados com o ciclo de vida de $P$. flavipes e precipitação pluviométrica média mensal, média diária, acumulada mensal, dias de precipitação e normais para a região de setembro de 2005 a agosto de 2006 são apresentados no Quadro 2. Em todas as propriedades onde ocorreram os surtos as áreas apresentavam vegetação seca e grande quantidade de larvas de Perreyia flavipes (Fig.1), observadas se deslocando nas primeiras horas da manhã em grupos aproximadamente 100 larvas. Nessas áreas não havia plantas hepatotóxicas conhecidas como Cestrum parqui e Xanthium spp. comuns na região.

As propriedades estavam localizadas geograficamente nas microrregiões de Pelotas e Serras do Sudeste (IBGE 2005): Propriedade 1, Latitude S $31^{\circ} 25^{\prime} 42,3^{\prime \prime}$ e Longitude WO 52०40'006"; Propriedade 2, Latitude S $31^{\circ} 17^{\prime} 19,2^{\prime \prime}$ e Longitude WO 52 $52^{\prime} 10,7^{\prime \prime}$; e Propriedade 3 , Latitude S $31^{\circ} 22^{\prime} 21,3^{\prime \prime}$ e Longitude WO 52 $06^{\prime} 24,1^{\prime \prime}$.

\section{Sinais clínicos}

Os sinais clínicos observados caracterizaram-se por depressão, prostração, icterícia discreta, decúbito com movimentos de pedalagem e coma. A morte ocorria após curso clínico de 24-48 horas. Alguns animais foram encontrados mortos sem observação de sinais clínicos prévios. Outros animais apresentaram hiperexcitabilidade, tremores da cabeça e pescoço e agressividade.

\section{Patologia}

Na necropsia foi observado fígado aumentado de tamanho e com marcada acentuação do padrão lobular (Fig.2), tanto na superfície capsular como na de corte. Em alguns casos o fígado apresentava-se pálido e em outros casos vermelho escuro. Alguns animais apresentaram retenção biliar com distensão da vesícula e edema da parede, que se estendia até o colédoco e mesentério adjacente. Os linfonodos hepáticos e mesentéricos esta- vam edemaciados e líquido seroso fluía ao corte. Observou-se, ainda, no intestino delgado, em 2 animais necropsiados, a mucosa enrugada, edematosa, avermelhada e as placas de Peyer deprimidas. Os vasos sangüíneos da serosa do intestino e do mesentério estavam ingurgitados. O conteúdo do cólon e do reto estava seco, e sangue e muco eram observados na luz desses órgãos. Hemorragias petequiais e equimóticas foram observadas nas serosas da cavidade abdominal, saco pericárdico, pericárdio e endocárdio.

O conteúdo dos pré-estômagos de um dos animais necropsiados colocado em um recipiente com água demonstrou a presença de fragmentos não digeridos das larvas, geralmente cabeça e porções do corpo.

Histologicamente foi observada necrose hepática hemorrágica que apresentava padrão centrolobular em alguns casos estendendo-se a região mediozonal, ou era massivo, restando uma ou duas camadas de hepatócitos

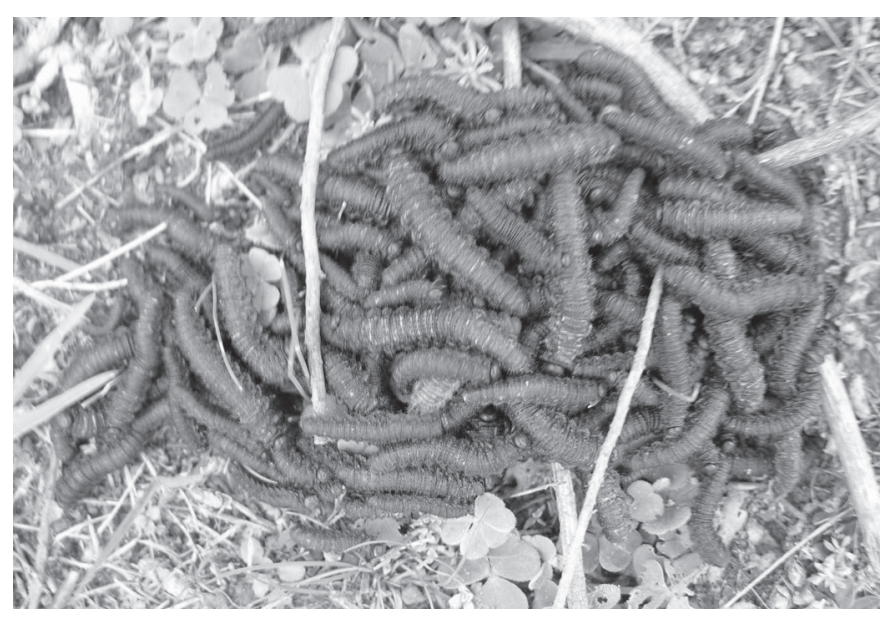

Fig.1. Grupo de larvas de Perreyia flavipes sobre a vegetação na Propriedade 3. 


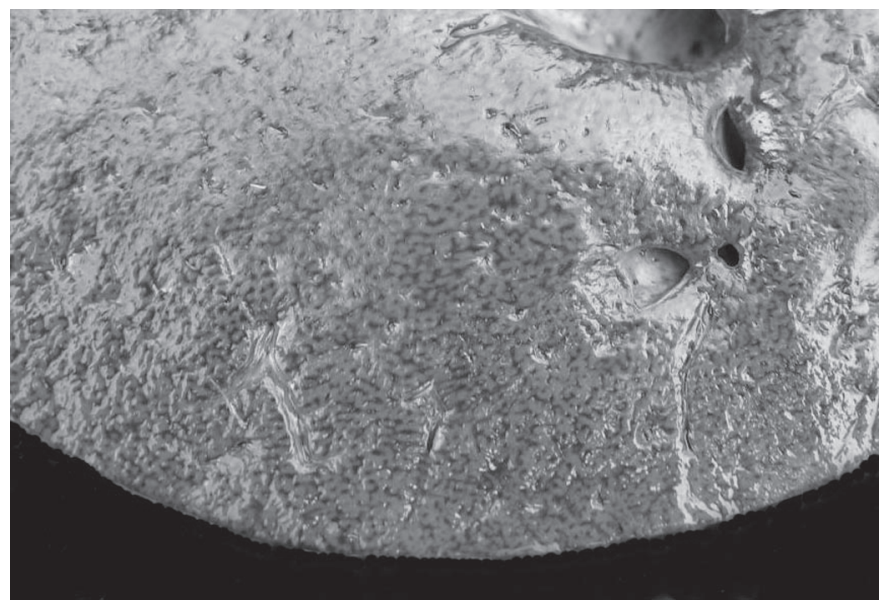

Fig.2. Fígado de bovino da Propriedade 1, intoxicado por Perreyia flavipes com acentuação do padrão lobular.

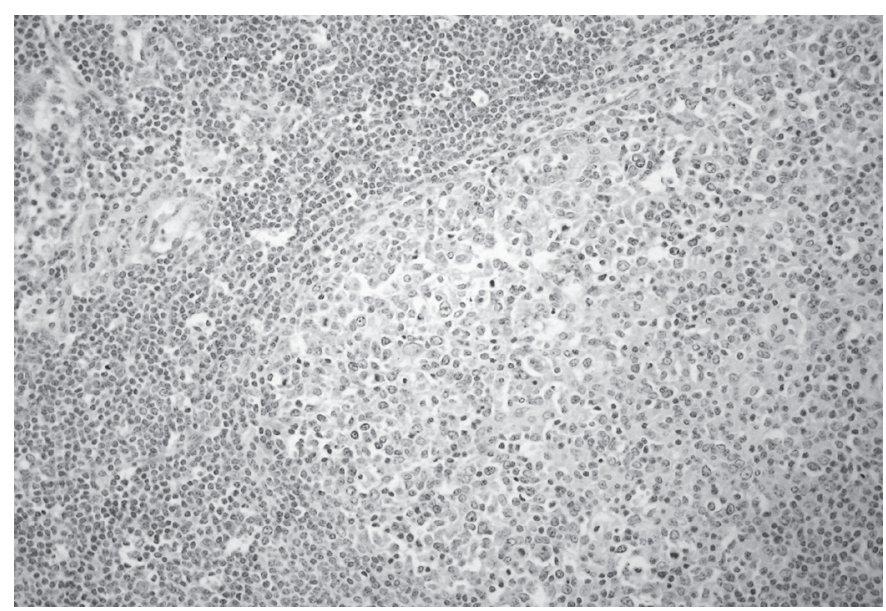

Fig.3. Necrose e depleção linfóide do centro germinativo de linfonodo de um bovino da Propriedade 2 intoxicado por Perreyia flavipes.

vacuolizados ao redor dos espaços porta. Havia hiperplasia dos ductos biliares, marcada hemossiderose e os hepatócitos das áreas remanescentes encontravam-se degenerados e nas áreas de necrose havia discreta infiltração de células mononucleares e polimorfonucleares. Observou-se, também, rarefação e necrose dos centros germinativos dos linfonodos (Fig.3), da polpa branca do baço e das placas de Peyer. Nos linfonodos os sinusóides estavam dilatados devido ao edema e havia, ainda, marcada hemossiderose principalmente na região cortical e hilo. Os rins apresentavam dilatação tubular, necrose do epitélio tubular e cilindros hialinos.

\section{DISCUSSÃO}

O diagnóstico da intoxicação por Perreyia flavipes foi realizado com base nos sinais clínicos, patologia e presença de grande quantidade de larvas nas áreas onde ocorreram os surtos, nas quais não havia outras plantas que causam necrose hepática comuns na região como Cestrum parqui e Xanthium spp.
A intoxicação ocorreu provavelmente como conseqüência da intensa seca ocorrida na região nos meses de outubro a dezembro de 2005, que permitiu a viabilidade das larvas nos casulos. Com a baixa precipitação no período de pupagem com médias diárias baixas e distribuídas durante um maior número de dias durante estes meses houve, provavelmente, menor mortalidade de larvas no casulo por afogamento e conseqüentemente maior emergência de adultos e maior número de posturas. As precipitações ocorridas durante o período de incubação dos ovos e primeiros estágios larvais propiciaram o crescimento exuberante da vegetação ofertando umidade adequada e abundante matéria vegetal em decomposição para as larvas nos primeiros estágios de vida. Isso é reforçado pelo fato de que 2 dos 3 surtos ocorreram em uma mesma microrregião (Pelotas) e um terceiro ocorreu na mesma microrregião (Serras do Sudeste) onde foi descrito um surto em ovinos no município de Encruzilhada do Sul (Raymundo et al. 2008), nas quais as condições climáticas são similares. No Uruguai foram descritos 46 surtos em 3 anos sendo sugerido que os excessos de chuvas na primavera com escassas precipitações no outono favoreceriam a ocorrência da intoxicação (Dutra et al. 1997, Dutra 2003), entretanto nos casos relatados neste trabalho os surtos ocorreram quando houve seca a partir de outubro. Durante os meses de verão houve precipitações próximas do normal favorecendo o crescimento da vegetação que servirá de alimento às larvas.

$\mathrm{Na}$ Propriedade 3 havia relato de morte de ovinos, entretanto não foi possível confirmar se essas mortes ocorreram em conseqüência da intoxicação por $P$. flavipes uma vez que os animais não foram necropsiados $e$ tampouco foi remetido material ao laboratório. No Uruguai em um relato da intoxicação foi sugerido que ovinos são menos afetados que bovinos, já que apenas em 2 de 6 estabelecimentos houve mortalidade de ovinos devido à intoxicação (Dutra et al. 1997). Por outro lado, Raymundo et al. (2008) relatam um surto dessa intoxicação em ovinos no ano 2006 no município de Encruzilhada do Sul e sugerem que hábitos alimentares poderiam ter influenciado na ocorrência da doença nesta espécie e não em bovinos que pastoreavam na mesma área.

Aparentemente, os surtos não são freqüentes, porém não pode ser descartada a possibilidade de que a intoxicação por $P$. flavipes tenha ocorrido na região em anos anteriores e as mortes tenham sido atribuídas a outras enfermidades de evolução aguda ou subaguda. É evidente, no entanto, que condições climáticas especiais são necessárias para a ocorrência da intoxicação.

É provável que os animais ingiram inicialmente as larvas misturadas junto à vegetação e após, devido provavelmente a palatabilidade, os animais passam a procurar os grupos de larvas que se encontram na vegetação nas primeiras horas da manhã, ou enquanto há umidade na pastagem. Este fato foi evidenciado, também, durante a intoxicação experimental em suínos, os quais após ingerirem as larvas misturadas à ração passaram a ingeri-las 
espontânea e avidamente sem a necessidade de misturálas a outros alimentos (Soares et al. 2000).

Tanto os sinais clínicos como os achados macroscópicos e histológicos desta intoxicação são similares aos observados nas intoxicações por plantas hepatotóxicas presentes na região como Cestrum parqui (Riet-Correa et al. 1986) que é um arbusto comumente encontrado em beiras de matas e Xanthium spp. (Méndez et al 1998, Driemeier et al. 1999) que geralmente causa surtos de intoxicação quando, após enchentes, em encostas de arroios ou rios anteriormente alagadas, ocorre a germinação da planta e os cotilédones são ingeridos. Histologicamente é comum a essas duas intoxicações a necrose de coagulação no fígado que pode apresentar padrões centrolobular se estendendo a medizonal ou massivo. No entanto, na intoxicação por $P$. flavipes ocorre necrose dos centros germinativos dos linfonodos, da polpa branca do baço e das placas de Peyer no intestino. Outras causas de necrose hepática aguda como a intoxicação por algas verde-azuladas (Microcystis aeruginosa) não têm sido observadas na região.

Para evitar-se a intoxicação os animais devem ser retirados dos potreiros onde houver larvas em grande quantidade e principalmente se há pouca disponibilidade de forragem. Ao inspecionar-se as pastagens deve considerar-se que os grupos de larvas são observados nas primeiras horas da manhã, final da tarde ou em dias nublados quando a umidade permanece sobre a vegetação. Pastagens de inverno feitas com a aração do solo podem ser um local seguro para os animais quando ocorrerem surtos de intoxicação, pois a aração do solo restringe a disponibilidade de alimento em decomposição para as larvas nos primeiros estágios de vida já que nesta fase as larvas são mais exigentes na sua alimentação. Quando as condições climáticas são favoráveis à ocorrência da intoxicação as pastagens devem ser manejadas de maneira que não haja excesso de matéria vegetal em decomposição no verão e outono, restringindo desta forma as condições de vida para os primeiros estágios larvais.

\section{REFERÊNCIAS}

Driemeier D., Irigoyen L.F., Loretti A.P., Colodel E.M. \& Barros C.S.L. 1999. Intoxicação espontânea pelos frutos de Xanthium cavanillesii em bovinos no Rio Grande do Sul. Pesq. Vet. Bras. 19(1):12-18.

Dutra F., Riet-Correa F., Mendez M.C. \& Paiva N. 1997. Poisoning of cattle and sheep in Uruguay by sawfly (Perreyia flavipes) larvae. Vet. Hum. Toxicol. 39:281-286.

Dutra F. 2003. Intoxicación por larvas de Perreyia flavipes en bovinos e ovinos, caracterización de la enfermedad y biología del insecto. Veterinaria, Montevideo, 38(152-153):7-24.

IBGE 2005. União Federal, Mesorregião, Microrregião e Município, Rio Grande do Sul. http://www.ibge.gov.br. Disponível em: 24.10.2007.

McKenzie R.A., Dunster P.J., Twist J.O., Dimmock C.K., Oelrichs P.B., Rogers R.J. \& Reichmann C.K. 1985. The toxicity of sawfly larvae (Lophyrotoma interrupta) to cattle. Qld Dept. Prim. Ind. Bull. QB85001:1-48.

Méndez M.C., dos Santos R.C. \& Riet-Correa F. 1998. Intoxication by Xanthium cavanillesii in cattle and sheep in Southern Brazil. Vet. Human Toxicol. 40:144-147.

Oelrichs P.B., MacLeod J.K., Seawright A.A., Moore M.R., Ng J.C., Dutra F., Riet-Correa F., Mendez M.C. \& Thamsborg S.M. 1999. Unique Toxic Peptides isolated from sawfly larvae in three continents. Toxicon 37:536-544.

Raymundo D.L., Bezerra Junior P.S., Bandarra P.M., Pedroso P.M.O., Oliveira E.C., Pescador C.A. \& Driemeier D. 2008. Spontaneous poisoning by larvae of Perreyia flavipes (Pergidae) in sheep. Pesq. Vet. Bras. 28. (Em publicação)

Riet-Correa F., Schild A.L. \& Méndez M.C. 1986. Intoxicação por Cestrum parqui (Solanaceae) em bovinos no Rio Grande do Sul. Pesq. Vet. Bras. 6(4):111-115.

Rodrigues Camargo O. 1955. Contribuição ao estudo do Tenthredinideo "Mata Porcos", Paraperreyia dorsuaria (Konow, 1899), no Rio Grande do Sul, Tese, Escola de Agronomia e Veterinária da Universidade do Rio Grande do Sul, Porto Alegre.

Smith D.R. 1990. A synopsis of the sawflies (Hymenoptera, Symphyta of the America South of the United States: Pergidae. Revta Bras. Entomol. 34:7-200.

Soares M.P., Riet-Correa F., Smith D.R., Pereira Soares M., Mendez M.C. \& Brandolt A.L. 2000. Experimental intoxication by larvae of Perreyia flavipes Konow, 1899 (Hymenoptera: Pergidae) in pigs and some aspects on its biology. Toxicon 39669-678.

Thamsborg S.M., Jorgensen R.J. \& Brummerstedt E. 1987. Sawfly poisoning in sheep and goats. Vet. Rec. 12:253-255. 